\title{
Correction to: A pheochromocytoma wrapped in an IgG4-related disease
}

\author{
Anne-Cécile Paepegaey ${ }^{1,2} \cdot$ Anne-Segolene Cottereau ${ }^{3} \cdot$ Anthony Dohan $^{4} \cdot$ Sébastien Gaujoux ${ }^{5}$. \\ Marie-Francoise Triller $^{6} \cdot$ Mathilde Sibony $^{6} \cdot$ Lionel Groussin $^{1,2} \cdot$ Rossella Libé $^{1,2,7}$
}

Published online: 6 November 2020

(C) Springer-Verlag GmbH Germany, part of Springer Nature 2020

\section{Correction to: European Journal of Nuclear Medicine and Molecular Imaging https://doi.org/10.1007/s00259-020-04959-9}

The figure is missing in the original manuscript, the figure is shown below.

This article is part of the Topical Collection on Erratum.

The online version of the original article can be found at https://oi.org/ 10.1007/s00259-020-04959-9

Rossella Libé

rossella.libe@aphp.fr

1 Department of Endocrinology, Cochin Hospital, Assistance Publique Hôpitaux de Paris, Paris Descartes University, Paris, France

2 Université Paris Descartes, Sorbonne Paris Cité, Paris, France

3 Department of Nuclear Medicine, Cochin Hospital, Assistance Publique Hôpitaux de Paris, Paris Descartes University, Paris, France

4 Department of Radiology, Cochin Hospital, Assistance Publique Hôpitaux de Paris, Paris Descartes University, Paris, France

5 Department of Endocrine Surgery, Cochin Hospital, Assistance Publique Hôpitaux de Paris, Paris Descartes University, Paris, France

6 Department of Pathology, Cochin Hospital, Assistance Publique Hôpitaux de Paris, Paris Descartes University, Paris, France

7 French Network for Rare Adrenal Cancers-COMETE, Paris, France 


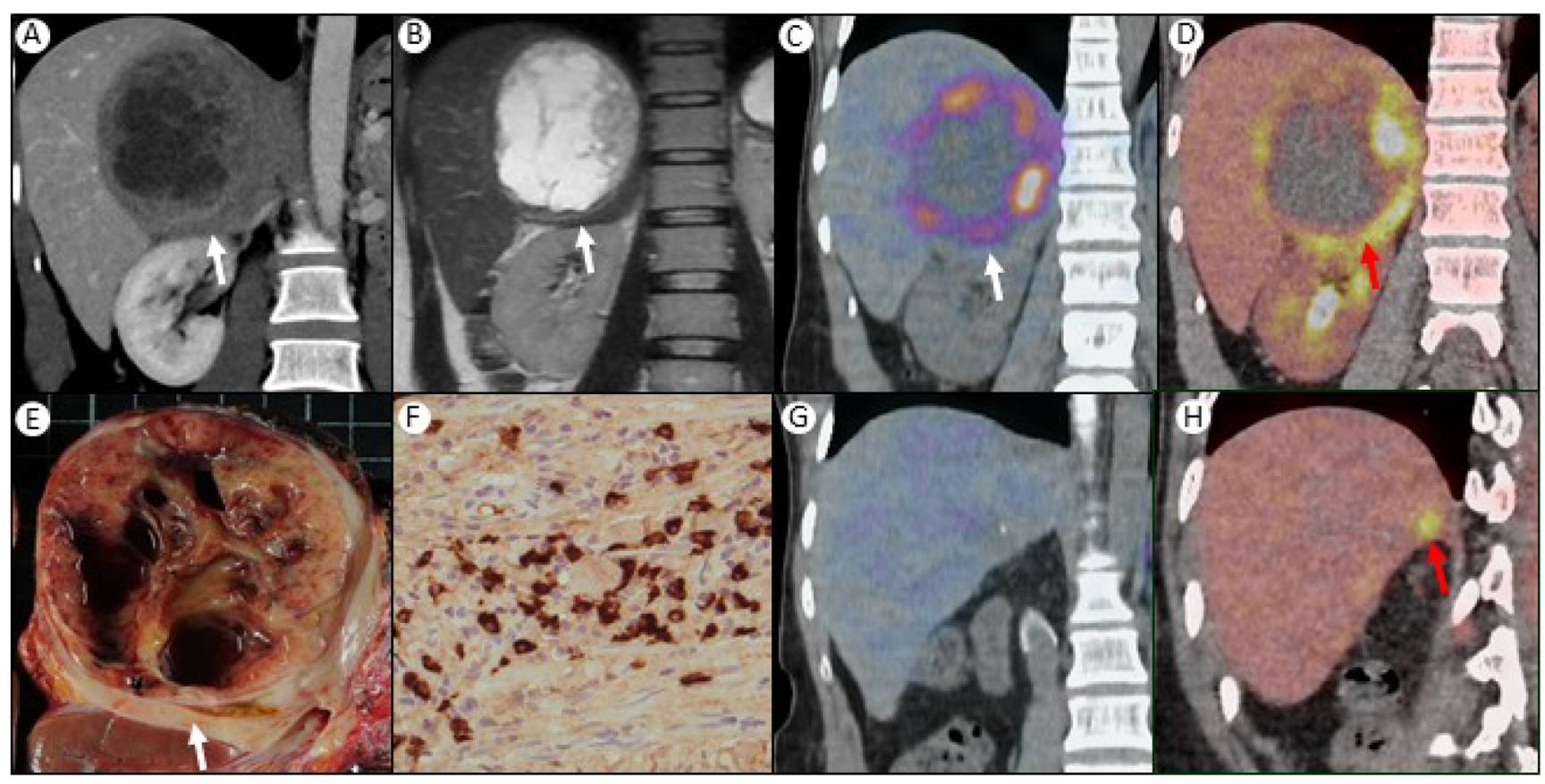

The original article has been corrected.

Publisher's note Springer Nature remains neutral with regard to jurisdictional claims in published maps and institutional affiliations. 